\title{
Commentary: Sifting the needles from the hay
}

\author{
Chadrick E. Denlinger, MD, ${ }^{\mathrm{a}}$ and Seth B. Krantz, $\mathrm{MD}^{\mathrm{b}}$
}

\author{
From the ${ }^{\mathrm{a} D i v i s i o n}$ of Cardiothoracic Surgery, Medical University of South Carolina, Charleston, SC; and ${ }^{\mathrm{b}}$ Divi- \\ sion of Thoracic Surgery, NorthShore University Health System, Evanston, Ill. \\ Disclosures: Authors have nothing to disclose with regard to commercial support. \\ Received for publication Oct 9, 2019; revisions received Oct 9, 2019; accepted for publication Oct 10, 2019; \\ available ahead of print Nov 14, 2019. \\ Address for reprints: Chadrick E. Denlinger, MD, Division of Cardiothoracic Surgery, Department of Surgery, \\ Medical University of South Carolina, 114 Doughty St, Charleston, SC 29425 (E-mail: denlinge@ musc.edu). \\ J Thorac Cardiovasc Surg 2020;159:1567-8 \\ $0022-5223 / \$ 36.00$ \\ Copyright (C) 2019 by The American Association for Thoracic Surgery \\ https://doi.org/10.1016/j.jtcvs.2019.10.056
}

The frequent use of diagnostic computed tomography (CT) scans for seemingly innumerable symptoms in addition to increased CT screening for lung cancer of high-risk individuals have contributed to the identification of millions of small pulmonary nodules. Although greater than $90 \%$ of these nodules are benign, that still means that $10 \%$ represent early-stage malignancies. ${ }^{1}$ A significant challenge in the management of these patients is the fact that many of these nodules are too small to reliably biopsy and are often below the resolution of positron emission tomography-CT. The ultimate solution to this issue may be diagnostic blood tests, and although academic institutions and medical industries are feverishly pursuing these "liquid biopsy" solutions, the specificity and sensitivity of each of these assays is prohibitively low for clinical application. ${ }^{2,3}$ As a result, the management of small pulmonary nodules still depends on sound clinical judgment that is ultimately supported by evidence to optimize the diagnosis of earlystage malignancy while at the same time avoiding both overtreatment of indolent disease and unnecessary diagnostic and invasive procedures on patients with benign disease. These "risks" are frequently cited by critics of lung cancer screening, and minimizing them is important if lung cancer screening is to become more widely adopted.

Although lung cancer screening with CT imaging saves lives by early detection of lung and other malignancies, 2 opposing concerns in managing small pulmonary nodules are (1) electing to follow nodules that turn out to be malignant and (2) electing to resect nodules that are benign. Madariaga and colleagues ${ }^{4}$ have published their results, demonstrating that their group was able to appropriately manage pulmonary nodules. Within the study, they followed 747 patients with both incidental and screendetected nodules within a single multidisciplinary clinic. Incidental patients represented 632 of 747 (85\%), and this group also had the greatest number of resections. Of the 104 resected incidental nodules, $21(20 \%)$ were benign. By comparison, 25 of the 115 patients with screen detected nodules were resected and only $1(4 \%)$ was benign. Three

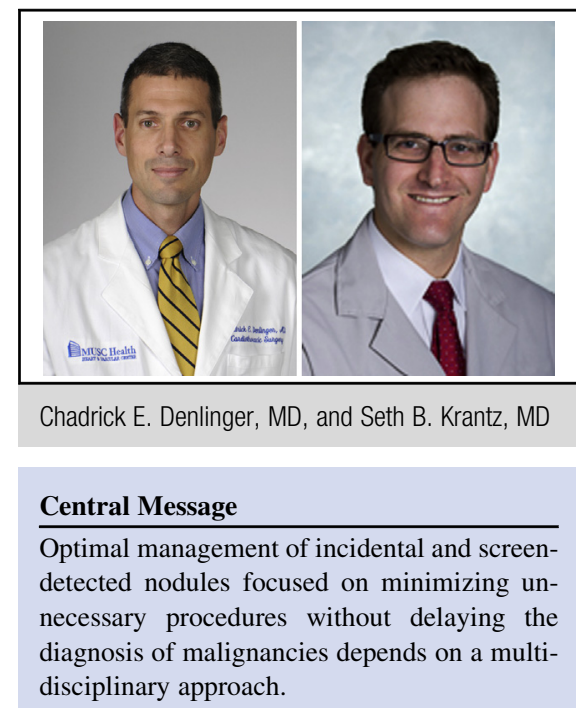

See Article page 1558.

of the patients undergoing resection for benign disease had a lobectomy because of the central location of the nodule. Importantly, the decision to follow incidental or screen-detected nodules did not result in a later presentation of advanced disease in any case. One limitation of the study is we do not yet have long-term follow-up of the nonsurgical patients. As most patients in pulmonary nodule clinics will be nonsurgical, the proper long-term management of these patients represents a key part of understanding best how to operative such programs.

Since the reporting of the National Lung Screening Trial 8 years ago, screening programs have become increasingly popular, with many screening programs also incorporating the management of incidentally detected nodules. The importance of the study by Madariaga and colleagues is that it serves as a model that can be emulated to maximize the treatment of early-stage disease and minimize interventions for patients with benign disease. The reporting of such outcomes will help establish benchmarks to which other screening programs measure against and ultimately contribute to acceptable standards for both benign resection rates and defining what may be an acceptable rate of initial observation of nodules that ultimately prove malignant. Along these lines, an issue raised in the study by Madariaga and colleagues that needs to be further explored in other investigations relates to the fact that $20 \%$ of the resected nodules in the incidental group were benign, which was substantially greater than the $4 \%$ benign resection rate in the screen-detected nodule group. Further exploration of 
this discrepancy will hopefully refine decision making leading to a reduced number of surgical interventions for benign lesions.

\section{References}

1. The National Lung Screening Trial Research Team. Reduced lung-cancer mortality with low-dose computed tomographic screening. N Engl J Med. 2011;365:395-409.
2. Tailor TD, Rao X, Campa MJ, Wang J, Gregory SG, Patz EF Jr. Whole exome sequencing of cell-free DNA for early lung cancer: a pilot study to differentiate benign from malignant CT-detected pulmonary lesions. Front Oncol. 2019;9:317.

3. Liang W, Zhao Y, Huang W, Liang H, Zeng H, He J. Liquid biopsy for early stage lung cancer. J Thorac Dis. 2018;10:S876-81.

4. Madariaga ML, Lennes IT, Best T, Shepard J-AO, Fintelmann FJ, Mathisen DJ, et al; the MGH Pulmonary Nodule Clinic Collaborative. Multidisciplinary selection of pulmonary nodules for surgical resection: diagnostic results and long-term outcomes. J Thorac Cardiovasc Surg. 2020;159:1558-66.e3. 